\title{
LABOR RELATIONSHIPS IN THE LIGHT OF THE COVID-19 PANDEMIC
}

\author{
Mohamed ELSAYED ELDESSOUKY \\ E-mail:col@afu.ac.ae; d.mdesoky@gmail.com \\ Associate Professor, PhD, Dean of Faculty of Law - Al Falah University, \\ Dubai, UAE
}

\begin{abstract}
There is no doubt that the COVID-19 pandemic, and government measures aimed at preventing the spread of the disease, have had a major impact on many areas, including tourism, aviation, hotels, restaurants, and factories, which have had an impact on work contracts in effect when the epidemic occurred. This paper exposes the most important effects of measures that countries have decided on to reduce the spread of COVID-19. Some of these measures led to the availability of the conditions of force majeure, in cases that lead to the impossibility of implementing labor contracts, whether it was a permanent or temporary impossibility, in whole or in part.
\end{abstract}

On the other hand, other measures have created conditions for applying the theory of unpredictability that led to rebalancing the obligations and rights of employers and workers so that workers alone do not bear the all of the negative consequences of these measures, thus it is important to highlight the role of the state in compensating employers for their losses that were paid in workers' salaries.

This paper also includes the adequacy of the current labor and social security laws to address the effects of epidemics on workers and employers, and concludes with a number of recommendations related to amending labor and social insurance laws to fill the legislative deficiency related to labor relations and protect workers in times of epidemics.

Key words: COVID-19, majeure force theory, the theory of unpredictability, labor law. 


\section{1- Introduction:}

There is no doubt that the COVID-19 pandemic and government measures aimed to preventing the spread of it, have had a major impact on many fields, as tourism, aviation, hotels, restaurants, and factories, which have in turn impacted work contracts in effect when the pandemic occurred.

This paper exposes the legal nature of COVID-19 and the precautionary measures aimed to prevent its spread and the effects of these measures. Some of these measures led to the availability of the conditions of force majeure, in cases that led to the impossibility of implementing labor contracts, whether it was a permanent or temporary impossibility, in whole or in part.

On the other hand, other measures have created conditions for applying the theory of emergency conditions that lead to rebalancing the obligations and rights of employers and workers so that workers alone do not bear all of the negative consequences of these measures, thus it is important to highlight the role of the state in compensating employers for their losses that were paid in workers' salaries.

It is also extremely important to evaluate the adequacy of existing labor and social security laws enacted to address the effects of pandemics on workers and employers. To determine the extent to which current labor and social security laws are appropriate to counter the legal effects of pandemics, including the COVID-19, as practical problems have arisen in which countries differed greatly in their confrontation.

\section{2- COVID-19 and the most important government measures to prevent its spread.:}

\subsection{What is COVID-19?}

COVID-19, a new strain of Coronavirus (World Health Organization, 2020) causes a respiratory infection in humans. It first occurred in China in December 2019, spreading widely around the world. Many sufferers have mild symptoms, while other groups have more severe symptoms.

\subsection{Several measures to reduce the spread of COVID-19:}

As a result of the World Health Organization (WHO) declaring COVID-19 a pandemic, governments have issued several measures to reduce its spread. These measures varied from country to country and even within the same country, as well as differing from time to time. Regarding labor relations, the most important of these measures are performing remote work, imposing curfews, closing some workplaces such as restaurants and hotels, reducing working hours, and imposing a maximum number of employees in the workplace.

In some work sectors, most of these measures did not violate the basic rights of workers related to salaries or vacations and did not result in the termination of work contracts. For example, in the case of universities and private schools the contracts continued in terms of continuing academic and administrative 
activities, through remote work. But many work sectors have been affected with the most of these measures having multiple negative impacts on the parties to labor relations.

The measures most affecting the business sector are the decisions to close some establishments and reduce work hours and the number of people allowed to be present in the workplace.

\subsection{The lockdown of workplaces and its impact on workers' rights}

The lockdown of the workplaces resulting from curfews and governmental decisions to lockdown some facilities, such as hotels, restaurants, and barber shops, raises the issue of their impact on existing labor contracts. Regarding the work contracts in force at the time of the government decisions, their implementation may be suspended throughout the closing period, and the workers may not be entitled to salaries. On the other hand, the closure may lead to financial difficulties for the employers, and they might permanently close their businesses. Therefore, it is very important to define the legal effects related to workers' rights in the light of the general legal rules for contracts, or those regulating labor relations as well as government measures issued to counter these effects.

\subsection{Reducing working hours, and imposing a maximum number of employees in the workplaces:}

Reducing working hours and imposing a maximum number of persons allowed to be present in the workplace has resulted in an increase in the number of workers compared to the jobs available in the labor market. Hence, employers began making decisions to alleviate the economic burden on the facility. Some workers are required to take their paid annual leaves, but if they do not have an annual leave balance, it is noted that some employers impose a leave with a salary of some employees, as well as restructure work contracts by reducing the number of working hours and wages.

\section{The legal nature of the effects of COVID-19 and precautionary measures to prevent its spread.}

The precautionary measures referred to above had an impact on work contracts, at times leading to the impossibility of implementing these contracts and other times causing some employers to bear substantial losses that made fulfilling their obligations towards employees a hardship. Therefore, it is important to determine the legal nature of these procedures for the purposes of properly applying general rules to work contracts under these exceptional circumstances Some of these measures fulfilled the conditions for applying force majeure theory and others fulfilled the conditions for applying the theory of unpredictability. If the measures result in the impossibility of implementing work contracts, then force majeure will apply, but if they result in the hardship of one of the contracting parties executing his commitment, it will be possible to apply the provisions of the theory of unpredictability. To determine which 
theory to apply, requires shedding light on both theories in terms of their concept and terms of their application.

\subsection{Force majeure}

\subsubsection{What is the force majeure?}

In the context of contract law, a force majeure can be defined as "an event or effect that can be neither anticipated nor controlled; especially, an unprecedented event that prevents someone from doing or completing something that he or she had agreed or officially planned to do. The term includes both, acts of nature (e.g. floods and hurricanes) and acts of people (e.g. riots, strikes and wars)" (Black \& Garner, 2019). In other words, force majeure refers to "events outside the control of the parties and which prevent one or both the parties from performing their contractual obligations" (Mathew, 2020)

\subsubsection{When do the provisions of force majeure apply to?}

In civil law states, such as the United Arab Emirates, France, Egypt, the concept of force majeure can be followed by a party to the contract as a legal matter that applies by law even without being explicitly defined in a contract. For example, the Civil Code of the United Arab Emirates (Federal Law No. 5 of 1985) defines the definition and limits of force majeure and its consequences. On the other hand, in common law states such as USA, India, and England, the concept has no general meaning and will only work if it is included in the contract, and in accordance with the clear terms of the clause included in the contract. (Mathew, 2020)

Whether enforcing force majeure by force of law or by prior agreement by contract, force majeure event must have been:

\section{- Unforeseeable and unavoidable}

It is stipulated in force majeure that its occurrence be unforeseeable and unavoidable. Even if a foreseeable event, such as floods or a pandemic occurs, it is not possible to avoid the implementation of force majeure because it is beyond a contract party's control, the party could not have avoided or overcome of its consequences.

\section{- An external event}

For the event to be force majeure, it must be external to the parties to the contract, preventing them from fulfilling their contractual obligations. This also means that none of the contracting parties contributed to the occurrence of the force majeure event. Accordingly, if the defendant caused the event that made the execution of the contract impossible or helped in the events occurrence, this event cannot be force majeure. For example, if an employer establishes a factory beside a river that is usually exposed to floods, in case of a flood occurring that results in the impossibility of implementing work contracts temporarily, then he is not entitled enact force majeure in order to not fulfill his obligations towards workers. (Hamad, 2006)

\section{- The Impossibility of fulfilling contract obligations}

This condition is a result of the two conditions above, meaning that if one of the parties to the contract could not expect force majeure, was unable to avoid its occurrence and did not violate his contractual obligations, it is very likely that he would be unable to implement his contractual obligations. On the one 
hand, this impossibility may be absolute, and on the other hand, it may be relative, that is, temporary or partial. Absolute impossibility means the impossibility of fully implementing the obligation, while in the case of temporary impossibility it is impossible to implement the obligation for a period of time while its implementation can be completed after the end of force majeure, meaning it is possible to partially fulfill the commitment.

\subsubsection{What is the impact of force majeure on contracts?}

If the force majeure is implemented, according to the above conditions, its impact varies according to the type of impossibility that results. If it is impossible to execute the contract at all, as a result of force majeure, the corresponding obligation must cease, and the contract is automatically canceled. Article 273(1) of the UAE Civil Code says, in part: "if force majeure supervenes which makes the performance of the contract impossible, the corresponding obligation shall cease, and the contract shall be automatically cancelled".

However, in the cases of temporary and partial impossibility arising from force majeure, the contract may not be terminated. In the temporary impossibility, the implementation of the contract can be suspended until the force majeure has ceased, but in the case of partial impossibility, only the part of the obligation that has been impossible to implement is impacted. Article 273(2) of the UAE Civil Code says, in part: "in the case of partial impossibility, that part of the contract which is impossible shall be extinguished, and the same shall apply to temporary impossibility in continuing contracts, and in those two cases it shall be permissible for the obligor to cancel the contract provided that the oblige is so aware."

\subsubsection{How can the precautionary measures be force majeure and what is} the impact of it on the current labor contracts?

The precautionary measures can be force majeure

It is envisaged that COVID-19 and the precautionary measures to prevent its spread will be a force majeure according to the above-mentioned conditions, but its effect on labor contracts varies according to the type of impossibility arising from it.

\section{The impact of force majeure on the current labor contracts}

Force majeure may lead to the absolute impossibility of implementing labor contracts, or it may lead to the temporary impossibility of them. If the impossibility is absolute, it will lead to the termination of the labor contract such as a collapse of a factory or hotel for a reason not attributed to the employer, However, if the impossibility of implementing the labor contract is relative, that is, temporary, such as closing of a restaurants and hotels, it does not lead to its termination, but rather to the suspension of its implementation. Although the impossibility of implementing the labor contracts resulting from measures to limit the spread of COVID-19 are temporary, but it is conceivable in some cases that it be permanent, for instance, if it led to the closure of a workplace. In such a case, it is impossible to implement the labor contract permanently for reasons that are not related to the employer or employee. 
Pursuant to this, Article 30 (3) of Labor Contract Regulation of Jiangsu Province in China stipulated that if the employment contract cannot be executed due to force majeure, the employment contract can be suspended. "During the suspension period, the employment relationship is preserved, and the performance of the labor contract is suspended. The employer may not pay wages and stop paying social insurance fees "(Ban, 2020)

In a few cases, the facilities may be closed, as in seasonal projects that continue for a few months of the year, such as the shops and restaurants within the Global Village in Dubai. This situation is dealt with under temporary work contracts.

\subsection{The theory of unpredictability" non haecin foedera veni": 3.2.1 What is the theory of unpredictability?}

The basic principle of a contract is an agreement to be saved pacta sunt servanda, Accordingly contractual obligations must be performed in good faith in order to ensure the stability of transactions in society.(Matefi \& Cernea, 2016) However, extraordinary and unforeseen circumstances may occur that cause a great loss to one of the contracting parties so that the implementation of the commitment is a hardship for him. At this point, justice may require modifying the agreed terms of the contract in a way that restores the balance between the obligations of the contracting parties. (Matefi \& Cernea, 2016) From this the theory of unpredictability has arisen. As it has been stipulated in the laws of some countries to give judges the power to amend the terms of contracts if certain conditions are met, while the laws of other countries stipulate that in order for this theory to be applied the application must be stipulated in the contract.

Many laws have regulated the theory of unpredictability, including Civil Transactions Law of the United Arab Emirates. In accordance with Article 249, the judge may, in the case of availability of the conditions of this theory, amend the terms of the contract in a way that restores the balance between the obligations of parties. He has the right to either reduce the obligations of the debtor or increase the obligations of the creditor ( $\mathrm{Al}$ Mansoury, 2017)The damaged parties have the right to go to the judiciary to restore the balance, The law gives the debtor the right to demand the application of this theory, if it was stipulated in the contract, and also allowed the judge to amend the terms of the contract to achieve a balance between its parties. However, some other laws do not recognize this theory, until recently. For instance, the French Civil Code, where the concept of hardship was introduced into French civil law as one of the main innovations of Decree No. 2016-131 of February 10, 2016, reforming the Civil Code provisions in respect to contract law, the general regime and the proof of obligations (the "Ordinance"), entered into force on the 1st of October 2016. (Pietrancosta, 2016) 


\subsubsection{The theory of unpredictability as a basis for amending some conditions of labor contracts:}

By applying the above to COVID-19 and the precautionary measures enacted to prevent its spread, to labor contracts, the terms of these contracts can be modified if they lead to severe losses to employers. Later, we will discuss the impact of unpredictability on labor contract clauses in terms of rebalancing the two parties to the employment contract and some of the obstacles that may face their application.

\section{Evaluation of employer's decisions to mitigate the negative economic impacts of COVID19 control measures}

Labor laws include a set of guarantees to prevent the employer from arbitrarily terminating labor contracts. The basic principle is that labor contracts are not terminated on the sole will of the parties. Nevertheless, if a force majeure is available that makes the implementation of the work contract impossible; this will lead to the termination of the contract, if certain conditions are met.

\subsection{Termination of labor contracts}

It is important to assess the extent to which the employer has the right to terminate labor contracts due to the previously mentioned effects of effects of COVID-19. This depends on determining the reasons for terminating the contract.

\subsubsection{Termination of labor contracts due to force majeure}

The basic principle is that labor contracts may not be terminated except for specific reasons, so that the employer may not arbitrarily terminate them. Force majeure is one of these reasons.

\subsection{Temporary suspension of labor contracts}

It may be impossible to implement the labor contracts in the midst of COVID19. This brings up the second case of the impossibility of implementing the contracts resulting from the force majeure. According to the force majeure theory, it is permissible to temporarily suspend the implementation of work contracts for the entire period of their impossibility.

When it is impossible to implement labor contracts due to curfew or closure decisions issued by governments, the contracts are not terminated. Rather they are not effective throughout the suspension period. The worker is not required to perform the work and the employer is not required to pay salaries, as the contract does not produce any obligations on the parties.

According to the foregoing, it can be said that, decisions issued by employers to suspend the implementation of labor contracts temporarily are valid in the countries where the force majeure theory is applied by force of law, but in countries that require to be agreed upon by the terms of the contract., the employer must agree with the worker. (Mathew, 2020)

\subsection{Imposing a leave of employees, or restructuring work contracts by reducing the number of working hours and wages}

As a result of governmental decisions to reduce working hours in many commercial and service industries, as well as to reduce the number of people 
present in the workplaces, many governments have issued temporary directives aimed at avoiding the effects of the COVID 19 crisis on labor relations.

For example, in the United Arab Emirates, for the purposes of organizing work relations in a manner commensurate with these epidemiological circumstances and strive to protect the interests of employers and workers, the Ministry of Human Resources and Emiratization issued Resolution No. 279 of 2020 regarding the stability of labor in private sector companies, during the period of applying the precautionary measures to contain the spread of COFID 19. This decision gives affected companies COVID-19 the right to restructure their contractual relationship with employees in a manner Interchanged according to the following progressive procedures:

- Give employees paid leave.

- Give employees unpaid leave

-Reducing salaries temporarily, the company must sign an additional supplement limited to the agreed period, or if the Ministry's decision is in effect, whichever is earlier.

Permanently reduce salaries - In such a case, the company must first obtain the approval of the Ministry by applying to amend employment contract data.

\subsubsection{Evaluating the amendment of some conditions of work contracts in the light of theory of unpredictability}

There is no doubt that COVID-19 and its resulting effects require the application of the theory of unpredictability to many work contracts, as some employers suffered heavy financial losses. Therefore, many governments have granted employers the right to make amendments to existing employment contracts to mitigate their losses.

Therefore. this theory is the legal basis for decisions related to amending some clauses of labor contracts, such as allowing employers to reduce salaries or request workers to obtain annual leave or impose leave without pay.

\section{Does the application of theory of unpredictability conflict with protecting the employees as a weaker party in labor relations?}

Labor laws are known to provide protection to workers because they are weaker party in labor relations regardless of a balance between their interests and that of the employers, regardless of establishing balance. However, this may be inconsistent with the application of the theory of unpredictability that aims to restore balance between the two contracting parties by the occurrence of an unexpected heavy loss for one of them.

The contradiction is clear between the theory of unpredictability, which is based on the principle of justice, and the labor laws that are keen to protect the worker. There is no doubt that this represents a problem that countries have faced because of the COVID-19 pandemic. The problem is how countries have faced this conflict between the considerations of justice that are in the interest of the employer, and considerations of the protection of workers? Many countries 
have overcome this problem by issuing decisions that take into account both considerations at the same time. On the one hand, they allocate funds to compensate workers for any financial damages resulting from the application of the unpredictability theory, and at the same time employers are compensated in the event that the application of this theory stops due to protecting workers from losing their salaries. I will show later examples of these decisions

As for the second question, is it the labor laws and social insurance laws need to be adjusted to protect workers in pandemic situations in a way that does not achieve significant financial losses for employers?

\section{Examples of decisions issued by states to protect workers from the economic consequences of measures to counter COVID-19}

The COVID-19 pandemic has shown disparities among countries of the world regarding the readiness of its laws to protect workers from the effects of pandemics. Some countries have protective legal systems that guarantee workers who are unemployed or whose salaries have decreased a reasonable level of financial support that enables them to obtain the necessary supplies for subsistence. While the pandemic showed the need in other countries to amend its labor laws as well as social security laws to achieve economic protection for workers.

Many countries did well to make decisions that compensate workers in a way that reduces the burden on employers and avoids raising many labor cases because of the delay in workers getting their benefits. The European Union countries accomplished this balance.

\subsection{Increasing amounts of temporary unemployment benefits in the event} of termination of labor contracts due to force majeure or economic reasons - In Belgium, The Federal Government issued a royal decree on April 14, 2020, that addressed the details of the National Security System during the period of the COVID-19 crisis, which includes the country's plan to grant some funds to combat the results of COVID-19.

According to this decree, temporary unemployment benefits (for compelling or economic reasons) were increased from $65 \%$ to $70 \%$ of the average income. Ceiling remains 2,754.76 euro per month An additional increase was added with a total value of 150 euros per month, the aggrieved worker was granted a total amount of 1,450 euros per month before processing his application, in the period before June 6, 2020.

German law provided the option for enterprises with economic hardships to reduce employee working time (if previously permitted in an individual or collective agreement) rather than terminating it and thus achieving economic relief by reducing or even abandoning employee costs. Under certain 
circumstances, the affected employees are entitled to social security benefits (technically paid by the employer Who can offset his expenses from the labor administration in order to offset the loss $60 \%$ to $67 \%$ of the net income. This mechanism seeks to avoid unemployment and secure a well-trained workforce. As a model, this tool has already been successfully tested from 2009 to 2011 in the aftermath of the 2008-2009 global financial crisis and reached a peak of 1.5 million short-term workers at that time. (Krause \& Kühn, 2020)

\section{In USA: FEMA Supplemental Lost Wages Payments under Other Needs Assistance}

Unemployment is one of the most significant negative economic effects resulting from the COVID-19 crisis, so many countries, including the US, have activated the social role of the state. By launching a federal unemployment benefit administered by the Federal Emergency Management Agency (FEMA), the Lost Wages Assistance (LWA) program, (Probasco, 2020) which provides unemployment supplemental insurance benefits of $\$ 300$ to $\$ 400$ from August 1, 2020 through December 27, 2020. The government bears $\$ 300$ of it as a fund-based payment. Disaster Relief (DRF), states provide $\$ 100$, in supplemental funds or as part of regular weekly unemployment compensation for those eligible.

\subsection{In case the work contract is suspended, the employer will pay part of the salary on behalf of the competent authority}

In Germany, as a result of the COVID-19 crisis and the resulting measures, the authorities issued laws specifically designed for the crisis at the federal level, some of which are related to labor relations, called the "social protection package". According to these laws, the employer must pay the wage if the worker is not able to perform his work for a reason that is not related to him or to the employer, so the employee can claim compensation, which the employer pays on behalf of the e Federal Ministry of Labor and Social Affairs (BMAS). (Krause \& Kühn, 2020)

\subsection{Expansion of emergency medical and family leaves}

COVID-19 has given rise to new work relationship problems, including quarantining employees who have had contact with an infected person, the need for someone to take time off to care for an infected relative, or to take care of children after schools and nurseries closed. In these situations, if the employee has no balance of leave for employees, he will lose his salary.

So, the United States passed the Families First Coronavirus Response Act (Lowey, 2020), One of the most important features of this law is that employees who work for employers who have fewer than 500 employees and 30 days of work are entitled to up to 12 weeks of protected leave to care for an at-risk 
family member who complies with quarantine requirements, recommendations, or

to take care of an employee's child if the child's school or daycare provider is closed due to coronavirus. After two weeks of paid sick leave, employers will pay a bonus of two-thirds of the employee's wages for the remainder of the leave. (Lewis Law Office, 2020)

\subsection{An employee may not be dismissed during his illness or quarantine period:}

According to Article 40 and Article 41 of the Labor Law in China, employee dismissal is not permitted in the following cases: (1) confirmed patients, suspected patients, and close contacts during treatment in isolation or medical supervision (2) workers who are unable to provide regular work due to isolation measures implemented by the government, or other emergency measures. during this period. (Ban, 2020)

5.5 State compensation for employers to avoid financial loss to employees: For the purpose of achieving employment stability and to mitigate financial difficulties for both employers and employees, the government in China has issued decisions authorizing provinces (except for Hubei Province) to reduce or exempt contributions from medium, small and micro enterprises from the payment for some types of social insurance contributions by no more than five months. With regard to large enterprises, they may be exempted from half of their contributions for specific types of social insurance for a period not exceeding three months. On the other hand, institutions that have experienced great financial difficulties may be exempted from postponing payment of social insurance contributions without paying a delay fine. (Ban, 2020)

\section{The suitability of existing labor and social security laws to counter the effects of pandemics on workers and employers:}

It is important to determine the extent to which current labor and social security laws are appropriate to counter legal effects from pandemics, including the coronavirus, as practical problems have arisen in which countries differed greatly in their confrontation of the situation. There are countries with systems of insurance and social security, able to cope with the economic consequences of pandemics, whether for employers or workers. Unlike other countries, the crisis showed that legislative amendments are needed to confront the economic effects of such crises. For example, the Georgian legislation does not include social security measures related to unemployment. The legislation does not regulate unemployment benefits or assistance to compensate for the loss of workers;' income. However, the government has announced that it will soon propose measures that focus primarily on providing financial support to workers who have lost their jobs. It is important that these relief programs not only cover dismissed employees, but also include suspended employees (Shvelidze, 2020) 


\subsection{A legislative vacuum in labor relations has been demonstrated by a COVID-19 pandemic}

\section{1 .1 Reduced wages and leave without pay:}

As previously indicated, because of the closure of some workplace or the reduction in the number of workers allowed to be present in the workplace a problem of conflict of interest has arisen between both employers and workers. Some laws have required the worker to take leave without pay if he is not having leave balance, or reduction of salaries. However, solving the problem by agreement between the employer and the worker is not in the interest of the worker as the weaker party, though he may accept conditions that are not in his favor in order not to lose his job or to avoid abuse by the employer.

\subsubsection{Is it permissible for an employee to receive a salary during the home quarantine?}

Doubt may arise that the employee was exposed to COVID-19 infection, possibly due to contact with a patient, and as a result he must adhere to quarantine. If it is not possible to do the work remotely, the question is whether he is entitled to a salary.

The answer to this question does not constitute difficulty in cases where the employee is infected with the COVID-19, where we have one of two assumptions, the first of which is that there is no relationship between work and infection, then the provisions of sick leave are applied, while with the second hypothesis, if it is proven that there is a causal relationship between work and infection, the provisions of a work injury can be applied for the fulfillment of its conditions.

While in cases where the infection is not proven, but the worker was in contact with one of the contagious person, and the worker was absent from work due to the quarantine, a distinction must be made between two cases. The first is that if the employee is in contact with a person who has no relationship with the workplace, the provisions of sick leave do not apply as long as his illness is not proven, but, he may obtain one of the types of licenses regulated by the Labor Laws. In the second case when the employee was in contact with one of his colleagues, he found that he had contracted the coronavirus and asked him to adhere to the quarantine; the worker deserves a paid vacation that is not deducted from his leave credit.

\subsubsection{Worker's absence from work due to fear of coronavirus infection}

Labor laws include provisions that give the worker the right to refuse to implement employers' instructions if he or she will be in imminent danger. Here the question arises whether These laws give the employee the right to refuse to be in the workplace for fear of COVID-19 because it represents an imminent danger? I think that just going to the workplace cannot be considered an 
imminent danger in the event of COVID-19 pandemic, if the employer fulfills his obligations to provide safety factors in the workplace. At the time of pandemics, no employer can eliminate the risk of its spread, Rather, if it is considered that being in the workplace is considered an imminent danger, despite the employer's commitment to safety instructions, then justice requires not to pay the wages of employees who are absent from work for fear of injury except If they are on their annual leave. (Davis et al., 2020)

\subsubsection{An employee may need an unusual leave to take care of some of his family members:}

As I mentioned above, as a result of COVID-19, new problems have appeared in work relations, including the need for an employee who has no leave balance, to obtain leave without losing his salary to care for a family member if he is infected with a viral infection, or to take care of a child after school closures and homes the nursery. Since it is not customary to stipulate these leave in labor laws, it is important to find a legal way to confront such a problem in times of the epidemic in a way that achieves the social and economic interest of the employee while not economically harming the employer, and we suggest here that this type of leaves be stipulated in labor laws With the provision of financial financing to ensure that the worker receives financial compensation during it, including the establishment of financial funds for this purpose or considering the circumstances of the epidemic as one of the social risks covered by social insurance laws.

\subsubsection{Conflict between the right of the infected employee to privacy and the right of other workers to be informed about his illness.}

The infected employee, in accordance with the health procedures, shall inform the competent authority of the names of those in contact with him in the fourteen days prior to the onset of symptoms. Striking a balance between the worker's right to privacy and following preventive health measures requires setting controls over the worker's obligation to inform about his infection.

\subsection{The necessity of amending the laws regulating labor and social insurance relations during epidemic periods}

Labor laws have regulated labor relations between employers and workers, but the COVID-19 pandemic has revealed many problems that require legislative intervention to ensure that workers' rights are protected in times of the pandemics, to avoid employers' decisions that may be unfair. On the other hand, these amendments include setting up special regulations to be applied in exceptional circumstances such as the COVID-19 pandemic. This may include reorganizing vacations, protecting the worker's right to privacy related his health data, increasing the maximum permissible sick leave, and setting controls for agreeing to reduce wages of employees. 
Even in cases in which the decisions issued by employers are legitimate, meaning that they do not violate labor laws, the role of laws regulating social insurance may come into effect, and these, in turn, may need to be reviewed, especially in countries that lack advanced social security systems. This may include amending them to include the amounts deducted monthly as contributions to social insurance to cover risks that arise to employees, such as loss of work or reduction of salaries, that arise due to epidemics.

\section{7- Conclusion}

This paper showed the effects of COVID-19 pandemic, and government measures aimed at preventing the spread of it. Some measures were a force majeure, resulting in the impossibility of implementing some labor contracts. The effect of this was discussed in terms of terminating or suspending some of them. Some laws dealing with these effects in terms of providing economic protection to the affected employees were reviewed.

On the other hand, other measures have created conditions for applying the theory of emergency conditions that leaded to rebalancing the obligations and rights of employers and workers so that workers alone do not bear the negative consequences of these measures. This highlighted the role of the state in compensating employers for their losses that were paid in workers' salaries.

This paper also covered some of the problems caused by the COVID-19 and the measures taken to prevent its spread, which show that it is necessary to amend labor laws and social insurance in some countries to achieve the interests of employees and employers in times of pandemics.

Furthermore, it is recommend that labor laws need to include special regulation of labor relations during pandemic periods. For example, stipulating an increase in the maximum permissible number of sick leaves for the employee who affected by the pandemic. In addition to the importance of striking a balance between the privacy of the infected employee's and the rights of his/her colleagues to know that they are contacting an infected person.

It also recommended increasing the risks covered by social insurance laws, particularly in the countries where the regulations lack of social security systems. Such regulations should include compensation for damages associated with pandemics, e.g. unemployment resulting from stopping or termination of labor contracts. 
References:

Al Mansoury, K. S. (2017). Theory of unpredictability and their effect on the economic equilibrium of the contract (an analytical study in the light of the UAE Civil Transactions Law)

Ban, X.Responding to the Impact of COVID-19 on Labor Relationship in China. retrieved from: http://www.cielolaboral.com/wpcontent/uploads/2020/04/china_noticias_cielo_coronavirus.pdf

Black, H. C., \& Garner, B. A. (2019). Black's law dictionary (Eleventh edition ed.). Thomson Reuters.

Davis, C. T., Goodboe, R. L., \& Martin, J. F. (2020). Can Employees Refuse to Return to Work Because of COVID-19? The National Law Review, X(299). retrieved from: https://www.natlawreview.com/article/can-employees-refuseto-return-to-work-because-COVID-19

Hamad, K. B. (2006). The Difference Between Force Majeure and unpredictability theory: A Comparative Study between Islamic Jurisprudence and Positive Law. Jordanian Journal of Islamic Studies, 2(1), 4. retrieved from: https://search.emarefa.net/detail/BIM289550

Krause, R., \& Kühn, J. W. (2020). COVID-19 and Labour Law: Germany. Italian Labour Law E-Journal, 13(1S), No 1S (2020): Special Issue: COVID-19 and Labour Law. A Global Review. 10.6092/issn. 1561-8048/10768

Lewis Law Office, L. (2020). Notes COVID19 Hiatus FMLA ADA FLSA. Lewis Law Office LLC. retrieved from: https://www.lexology.com/library/detail.aspx?g=9868f5483070-4866-a6b4-84b0ed35dd88

Lowey, N. M. (2020). Text - H.R.6201 - 116th Congress (2019-2020): Families First Coronavirus Response retrieved from: https://www.congress.gov/. https://www.congress.gov/bill/116t h-congress/house-bill/6201/text

Matefi, R., \& Cernea, L. (2016). The Theory of Unpredictability "NON HAECIN FOEDERA VENI. Bulletin of the Transilvania University of Braşov, Series VII: Social Sciences and Law, 9(1), 191-198. retrieved from: https://www.ceeol.com/search/article-detail?id=416395

Mathew, R. (2020). Force-Majeure under Contract Law in the Context of COVID-19 Pandemic. SSRN Electronic Journal, 10.2139/ssrn.3588338

Pietrancosta, A. (2016). Introduction of the hardship doctrine ("théorie de l'imprévision") into French contract law: A mere revolution on the books? Colloque, 3, 1-8.

Probasco, J. (2020). Could You Get Help From the Lost Wages Assistance (LWA) Program? Investopedia. retrieved from: https://www.investopedia.com/lost-wages-assistance-lwaprogram-definition-5076976 
Shvelidze, Z. (2020). COVID-19 and Labour Law: Georgia. Italian Labour Law E-Journal, 13(1S), No 1S (2020): Special Issue: COVID-19 and Labour Law. A Global Review. retrieved from: https://doi.org/10.6092/issn.1561-8048/10772

Website references:

World Health Organization. (2020). Coronavirus disease (COVID-19, retrieved from: https://www.who.int/news-room/q-adetail/coronavirus-disease-COVID-19, accessed on 8 October 2020. 